\title{
Manejo da irrigação no feijoeiro cultivado em plantio direto
}

\author{
Paulo C. R. da Cunha' ${ }^{1}$, Pedro M. da Silveira ${ }^{2}$, Jorge L. do Nascimento ${ }^{3}$ \& José Alves Júnior ${ }^{3}$
}

\begin{abstract}
RESUMO
Este trabalho foi desenvolvido com objetivo de se avaliar três formas de manejar a irrigação do feijoeiro. A cultivar de feijão preto BRS Supremo foi submetida ao manejo da irrigação por tensiometria, tanque Classe A e Penman-Monteith. Avaliaram-se a produtividade de grãos, número de vagens por planta, número de grãos por vagem, massa de 100 grãos, altura da planta, lâmina total e eficiência de uso da água. O método do tanque propiciou a maior lâmina acumulada e a maior frequência de irrigação. A lâmina total estimada por tensiometria foi 29,7 e 17,8\% menor que a estimada pelos métodos do tanque e de Penman-Monteith, respectivamente. Houve diferenças significativas quanto à produtividade de grãos, número de grãos por vagem e altura da planta. O método do tanque propiciou a obtenção de maiores produtividades enquanto o método da tensiometria levou à economia de água de irrigação ocorrendo, no entanto, redução da produtividade. Plantas de feijoeiro submetidas a déficit hídrico de 21 e $37 \%$, respectivamente, nas fases vegetativa e reprodutiva tiveram sua produtividade reduzida em $29 \%$. Déficit hídrico de $22 \%$ na fase reprodutiva reduziu a produtividade do feijoeiro em $15 \%$. Não foram observadas diferenças significativas na eficiência do uso da água.
\end{abstract}

Palavras-chave: Phaseolus vulgaris L., necessidades hídricas, tanque Classe A, Penman-Monteith

\section{Irrigation management in bean crop cultivated in no-tillage system}

\begin{abstract}
The objective of this research was to evaluate three methods of irrigation management in the bean crop. The variety of black bean BRS Supremo was submitted to irrigation management by tensiometry, Class A pan method, and Penman-Monteith. The productivity of grains, number of grains per plant, grains per berry, weight of 100 grains, height of plants, total water depth and water use efficiency were evaluated. The method of the Class A pan promoted the largest accumulated water depth and the largest irrigation frequency. The tensiometry underestimated in 29.7 and $17.8 \%$ the total water depth estimated by the Class A pan method, and Penman-Monteith, respectively. The results demonstrated that there were significant differences for the productivity of grains, number of grains per berry and height of plants. The Class A pan method favored larger productivities, while the tensiometry took the economy of irrigation water, having, however, reduction of the productivity. Bean plants subjected to water deficit of 21 and $37 \%$, respectively, in the vegetative and reproductive stages, have their productivity reduced by $29 \%$. Water deficit of $22 \%$ in the reproductive stage reduces the productivity by $15 \%$. There were no significant differences in the water use efficiency.
\end{abstract}

Key words: Phaseolus vulgaris L., water requirement, Class A pan, Penman-Monteith method

1 Instituto Federal Goiano, Câmpus Urutaí, Rodovia Geraldo Silva Nascimento, km 2,5, Zona Rural, CEP 75590-000, Urutaí, GO. Fone: (64) 3465-1900. E-mail: pcdacunha@hotmail.com

${ }^{2}$ Embrapa CNPAF, Rodovia GO 462, km 12, Zona Rural, CEP 75375-000, Santo Antônio de Goiás, GO. Fone: (62) 3533-2179. E-mail: pedro.silveira@embrapa.br

3 Escola de Agronomia e Engenharia de Alimentos/UFG, Câmpus Samambaia, Rodovia Goiânia/Nova Veneza, km 0, C. P. 131, CEP 74690-900, Goiânia, GO. Fone: (62) 3521-1534. E-mail: jln.agro@gmail.com; josealvesufg@yahoo.com.br 


\section{INTRODUÇÃO}

A cultura do feijoeiro (Phaseolus vulgaris L.) se destaca como um dos cultivos de maior importância no Brasil; por ser o feijão um produto agrícola extremamente apreciado pelos brasileiros, está inserido nos costumes culinários da Nação e é considerado alimento básico e uma das principais fontes de proteína na dieta da população.

A avaliação de sistemas de cultivo e de técnicas de manejo que potencializem a produção da cultura com o emprego de uma técnica como a irrigação assume, nos dias atuais, importância considerável devido à escassez de recursos hídricos e pelo fato da agricultura irrigada ser um dos setores que mais demandam água. A necessidade de se produzir com qualidade e em maior quantidade e a diminuição dos impactos ambientais negativos sobre o recurso natural 'água' exigem, da comunidade científica, novos conhecimentos sobre as reais necessidades hídricas das culturas (Reis et al., 2007; Morais et al., 2008; Santana et al., 2009).

Vários são os métodos para estimar a quantidade de água requerida pelo feijoeiro sendo também um dos mais acessíveis aos irrigantes, o tanque Classe $\mathrm{A}$. O método do tanque Classe A integra variáveis meteorológicas e da cultura e é de fácil execução. O tanque pode ser instalado no campo, próximo à cultura. Normalmente, apresenta valores superestimados da evapotranspiração com incrementos significativos na produtividade do feijoeiro (Pavani et al., 2008; Lopes et al., 2011).

A irrigação do feijoeiro também pode ser manejada por tensiometria em que medidas da tensão de água do solo são empregadas para cálculos indiretos da necessidade hídrica da cultura. O tensiômetro tem sido indicado como ótimo instrumento para manejo da irrigação do feijoeiro, vem sendo apontado como excelente método para estabelecer o momento e a quantidade de água da irrigação, principalmente por não exigir a determinação de dados meteorológicos, às vezes indisponíveis (Lopes et al., 2004).

Tais dados meteorológicos são indispensáveis para aplicação do modelo de Penman-Monteith; esta é a equação mais utilizada para estimativa da $\mathrm{ET}_{0} \mathrm{e}$ é recomendada pela FAO como método padrão (Reis et al., 2007). Sua aplicação, porém, não é tão simples como o tanque Classe A e a tensiometria pois necessita de maior número de dados obtidos de estações meteorológicas, ressaltando-se que tais equipamentos são de custo elevado e exigem operadores qualificados.

Mesmo com a existência dos métodos capazes de possibilitar o atendimento preciso das necessidades hídricas do feijoeiro, muitos agricultores ainda desconhecem as formas de realizar o manejo adequado da água no solo, sendo a quantidade de água aplicada determinada com base na experiência individual e empírica, resultando em valores que podem proporcionar lâminas inadequadas, com consequentes e ignorados decréscimos na produtividade da cultura.

Com base na importância de estudos capazes de gerar informações sobre as necessidades hídricas e o manejo da irrigação do feijoeiro cultivado em novos sistemas de cultivo, como o plantio direto no Cerrado, desenvolveu-se este trabalho com o objetivo de quantificar o desempenho de três formas de manejo da irrigação, tensiometria, tanque Classe A e PenmanMonteith, do feijoeiro cultivado no sistema de integração lavoura-pecuária, em Santo Antônio de Goiás, Goiás.

\section{Material e Métodos}

O experimento foi conduzido na área experimental da Fazenda Capivara, pertencente à Embrapa Arroz e Feijão, situada no município de Santo Antônio de Goiás, Goiás, (latitude: $16^{\circ} 29^{\prime} 15,6^{\prime \prime} \mathrm{S}$, longitude: $49^{\circ} 17^{\prime} 55,2^{\prime \prime} \mathrm{W}$ e altitude: $786 \mathrm{~m})$ no período de julho a outubro de 2007 em Latossolo Vermelho distroférrico. Segundo a classificação de Köppen, a região apresenta clima Aw, tropical de savana, megatérmico. A temperatura média anual é de $23,0^{\circ} \mathrm{C}$ e o mês de julho apresenta a menor média de temperaturas mínimas $\left(14,3{ }^{\circ} \mathrm{C}\right)$ enquanto o mês de setembro apresenta a maior média de temperaturas máximas $\left(31,5^{\circ} \mathrm{C}\right)$. O total médio anual de insolação é de 2318,9 h. O regime pluvial é bem definido, ou seja, período chuvoso de outubro a abril e período seco de maio a setembro. A precipitação pluvial média anual é de $1487 \mathrm{~mm}$ e a umidade relativa do ar, média anual, é de $71 \%$, com o mês de agosto apresentando o menor índice (49\%). A perda de água por evaporação, média anual, medida pelo tanque Classe A, é da ordem de $1915 \mathrm{~mm}$.

A cultura do feijoeiro foi conduzida em 6,29 ha de área cultivada e irrigada pelo sistema pivô central. O delineamento experimental empregado foi o inteiramente casualizado com nove parcelas de cada tratamento dispostas aleatoriamente em faixas demarcadas a partir do centro do pivô (Chacín Lugo, 1997). Os tratamentos empregados nas parcelas corresponderam a três métodos de manejo da irrigação, assim descritos: tensiometria, com tensão de irrigação de $35 \mathrm{kPa}$ (Silveira \& Stone, 1994); estimativa da evapotranspiração de referência $\left(\mathrm{ET}_{0}\right)$ a partir da evaporação diária do tanque Classe A (tanque), com adoção do coeficiente do tanque (kp) proposto por Snyder (1992) e coeficiente de cultura (kc) proposto por Stone \& Silva (1999) para feijoeiro irrigado cultivado em sistema de plantio direto e estimativa da $\mathrm{ET}_{0}$ a partir do modelo empírico de Penman-Monteith apresentado por Allen et al. (1998) e kc proposto por Stone \& Silva (1999). Os dados meteorológicos foram obtidos diariamente da estação meteorológica automatizada da Embrapa Arroz e Feijão, localizada a $780 \mathrm{~m}$ da área experimental.

As curvas características de retenção de água do solo foram elaboradas com o método da centrífuga, conforme descrito por Freitas Júnior \& Silva (1984), nas tensões de água correspondentes a 6, 8, 10, 33, 60, 100 e $1500 \mathrm{kPa}$ (EMBRAPA, 1997). As equações das curvas características de retenção de água do solo foram ajustadas conforme van Genuchten (1980), os coeficientes do ajuste das equações foram obtidos com o auxílio do software SWRC (Soil Water Retention Curve) versão 3.00 (Dourado Neto et al., 2001). Com as equações ajustadas foram determinados os coeficientes de ajuste das curvas de retenção, $\alpha(0,6295$ e 0,4922$), \mathrm{m}(0,2410$ e 0,2583$)$ e n $(1,3175$ e 1,3483$)$, para as profundidades $(0-0,15 \mathrm{~m}$ e $0,15-0,30 \mathrm{~m})$, respectivamente.

As umidades volumétricas na "capacidade de campo" $\left(\theta_{\text {cc }}\right)$, umidade crítica $\left(\theta_{\mathrm{c}}\right)$, e ponto de murcha permanente $\left(\theta_{\mathrm{pmp}}\right)$, foram 
obtidas empregando-se as curvas de retenção de água do solo para as tensões de 6,35 e $1.500 \mathrm{kPa}$, respectivamente sendo, na camada $0-0,15 \mathrm{~m}, \theta_{\text {cc }}, \theta_{\mathrm{c}}$ e $\theta_{\text {pmp }}$ de $0,4020,0,3650$ e 0,3115 $\mathrm{m}^{3} \mathrm{~m}^{-3}$, respectivamente e na camada $0,15-0,30 \mathrm{~m}$, de 0,3882 , 0,3521 e $0,3025 \mathrm{~m}^{3} \mathrm{~m}^{-3}$. Para estabelecimento e determinação da tensão matricial crítica adotou-se a recomendação de Silveira \& Stone (1994). Em todos os tratamentos foi adotada a lâmina de reposição de $10,96 \mathrm{~mm}$, que corresponde à água facilmente disponível, ou seja, a capacidade de armazenamento do solo entre as tensões referentes à "capacidade de campo" e a tensão crítica de $35 \mathrm{kPa}$.

A área se encontrava com cobertura de Brachiaria ruziziensis; já vinha sendo manejada durante três anos consecutivos no sistema integração lavoura-pecuária, milho em consórcio com Brachiaria ruziziensis no verão (Sistema Santa Fé) e feijão no inverno, com pastejo rotacionado no período de entressafra. Na semeadura do milho (híbrido AG 7000) foram semeados $10 \mathrm{~kg} \mathrm{ha}^{-1}$ de sementes de braquiária misturados ao adubo (400 $\mathrm{kg} \mathrm{ha}^{-1}$ de 4-30-16) e $3 \mathrm{~kg} \mathrm{ha}^{-1}$ de sementes da forrageira posicionadas entre as linhas de milho espaçadas $0,90 \mathrm{~m}$. Após trinta dias da colheita do milho foram introduzidos touros jovens da raça nelore; a área foi submetida ao pastejo até o final de junho. Após dessecação do material vegetal com aplicação do herbicida glyphosate (1440 $\mathrm{g} \mathrm{ha}^{-1}$ do i.a) realizou-se a semeadura do feijão, cultivar BRS Supremo sobre $11,2 \mathrm{Mg} \mathrm{ha}^{-1}$ de resíduos vegetais. A semeadura foi realizada mecanicamente em 6/7/2007, no espaçamento de $0,45 \mathrm{~m}$ entre linhas e 15 sementes $\mathrm{m}^{-1}$. A adubação básica nos sulcos de semeadura foi de $400 \mathrm{~kg} \mathrm{ha}^{-1}$ da fórmula 4-30-10, realizada levando-se em consideração as características químicas do solo e as recomendações de calagem e adubação de Barbosa Filho \& Silva (2000) para feijoeiro irrigado cultivado no Cerrado. Foram aplicados $90 \mathrm{~kg} \mathrm{ha}^{-1}$ de nitrogênio em cobertura parcelados em duas aplicações via fertigação, a primeira com plantas apresentando o terceiro trifólio totalmente expandido, estádio $\mathrm{V}_{(4-3)}$, e a segunda após emissão do sexto trifólio $\mathrm{V}_{(4-6)}$.

Foram aplicados inseticidas para o controle da moscabranca (Bemisia tabaci) e da vaquinha (Diabrotica speciosa). Para o controle de plantas daninhas foram efetuadas aplicações sequenciais dos herbicidas fluazifop-p-butil e fomesafen. Durante o desenvolvimento do feijoeiro foram realizados todos os tratos culturais e fitossanitários recomendados para a cultura do feijoeiro. Os estádios de desenvolvimento da cultura foram caracterizados segundo critérios estabelecidos por Fancelli \& Dourado Neto (1997).

Por ocasião da colheita, em 5/10/2007 (estádio R9) dez plantas por parcela foram coletadas e determinados os seguintes componentes: altura de plantas (medida do nível do solo ao ápice da planta); número de vagens planta $^{-1}$; número de sementes vagem $^{-1}$ e massa de 100 grãos. A produtividade de grãos foi determinada pela colheita de duas linhas com $3 \mathrm{~m}$ na área útil da parcela. A debulha foi feita manualmente. Determinou-se a umidade dos grãos e a produtividade foi corrigida para a umidade de $13 \%$. A eficiência no uso da água pela cultura foi calculada por meio da razão entre a produtividade média de grãos e o volume total de água recebido durante os 92 dias do ciclo da cultura.

De posse dos dados realizou-se a análise de variância para cada variável. Para as variáveis que mostraram efeito significativo dos tratamentos pelo teste $\mathrm{F}$, procedeu-se à comparação de médias pelo teste de Tukey a 0,05 de probabilidade.

\section{Resultados E Discussão}

Na Figura 1 estão apresentados os dados meteorológicos registrados diariamente durante a condução do experimento. A influência das condições meteorológicas sobre o consumo de água pelo feijoeiro ficou evidenciada durante os estádios R6 e R7; nesses períodos as plantas apresentavam desenvolvimento máximo de seu dossel vegetativo e, consequentemente, elevada
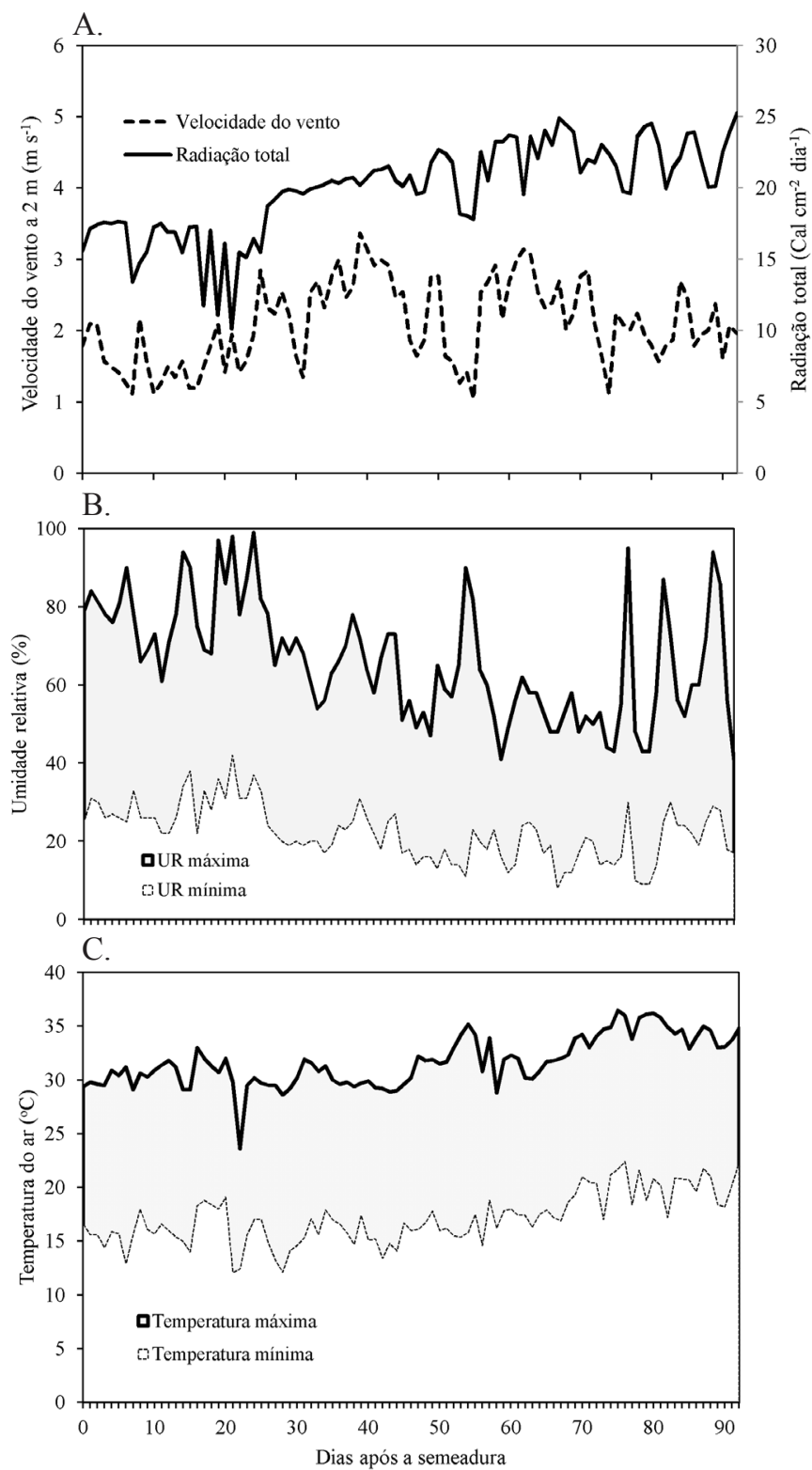

\begin{tabular}{cc|c|c|c|c|c|c|c|c|c|} 
Estádio & V0 & V1 & V2 & V3 & V4 & R5 & R6 & R7 & R8 & R9 \\
\hline Dias & 5 & 6 & 6 & 9 & 16 & 6 & 7 & 11 & 20 & 6
\end{tabular}

Figura 1. Condições meteorológicas durante o ciclo do feijoeiro semeado em 5/7/2007 em Santo Antônio de Goiás, Goiás. Radiação solar e velocidade do vento (A), umidades relativas máximas e mínimas (B) e temperaturas máximas e mínimas (C). Dados da estação automatizada da Embrapa Arroz e Feijão 
superfície transpiratória. Como referidos estádios coincidiram com a segunda quinzena de agosto, período de maior demanda atmosférica durante o ciclo da cultura, teve como resultado elevados valores de evapotranspiração.

As evapotranspirações médias estimadas por meio do tanque Classe A e de Penman-Monteith, foram de 4,43 e 3,71 mm d ${ }^{-1}$, respectivamente. Maiores taxas médias de evapotranspiração foram observadas após início da fase reprodutiva; estádio $\mathrm{R} 5$, tendo atingido valores máximos de 6,04 e $5,28 \mathrm{~mm} \mathrm{~d}^{-1}$ com os métodos do tanque Classe A e de Penman-Monteith, respectivamente, no estádio R6, com a cultura em pleno florescimento. Tais resultados se assemelham aos obtidos por Bizari et al. (2009) em condições de plantio direto, quando se constatou que o maior consumo médio diário pelo feijoeiro foi de $5,43 \mathrm{~mm}$, ocorrido durante a fase de enchimento de grãos; isto ocorre em função do maior índice de área foliar e da maior atividade fotossintética. Outros trabalhos demonstram que os maiores valores de evapotranspiração máxima para o feijoeiro ocorrem nos estádios de florescimento e de enchimento de vagens (Andrade et al., 2002; Lopes et al., 2004). No trabalho de Andrade et al. (2002) em condições de plantio direto foi verificada maior evapotranspiração diária, $5,93 \mathrm{~mm} \mathrm{~d}^{-1}$, por volta dos 62 dias após a emergência (DAE) sendo que, neste trabalho, o estádio R8 se estendeu dos 66 aos 86 DAE.

A distribuição das irrigações e das precipitações ao longo do ciclo da cultura é apresentada na Tabela 1. Conforme se observa, todos os tratamentos receberam lâminas líquidas médias de $6,39 \mathrm{~mm}$ aos 3, 7, 10, 13 e 16 dias após a semeadura (DAS); procedeu-se desta forma a fim de se iniciar o experimento com todas as parcelas contendo o mesmo teor de água no solo.

Logo após iniciado o manejo com os tratamentos (17 DAS) constatou-se ocorrência de precipitações pluviais das quais resultaram lâminas efetivas de 9 e 3,50 mm, respectivamente, aos três e seis dias após iniciada a aplicação dos métodos de manejo da irrigação. No estádio V3 as parcelas dos tratamentos tensiometria e Penman-Monteith receberam apenas água da chuva enquanto nas do tratamento tanque Classe $\mathrm{A}$ foi efetuada uma irrigação com lâmina de $10,96 \mathrm{~mm}$. No estádio V4 as parcelas que receberam as maiores lâminas de irrigação foram as manejadas por Penman-Monteith, com lâmina 10,96 mm superior às dos outros tratamentos. Durante a fase vegetativa as parcelas dos tratamentos tensiometria, tanque Classe A e Penman-Monteith receberam lâminas totais parciais de 81,69 , 103,61 e 103,61 mm, respectivamente.

Durante os seis dias em que a cultura permaneceu no estádio R5 as parcelas receberam lâminas apenas de irrigação, estádio no qual o manejo por tensiometria promoveu apenas duas irrigações com fornecimento de água 59,47\% menor que o das parcelas manejadas por tanque. Com Penman-Monteith foram feitas três irrigações nas quais foram aplicados 32,88 $\mathrm{mm}$; em comparação com o tratamento tanque houve um déficit de $39,20 \%$.

Com a cultura em plena floração não houve diferenciação de irrigações nem de lâminas com os tratamentos tanque Classe A e Penman-Monteith; no entanto, o tratamento tensiometria propiciou suprimento de água $12,95 \%$ inferior aos outros métodos. Como não houve ocorrência de precipitação nesse estádio, as menores lâminas aplicadas com os tratamentos tensiometria e Penman-Monteith em R5 e R6 resultaram, provavelmente, em déficit hídrico à cultura em período crítico. As maiores diferenças no número de irrigações e nas lâminas foram observadas durante o estádio mais longo da cultura, R8, o qual apresentou duração de vinte dias. Neste estádio, caracterizado pelo enchimento das vagens, se estabelecida comparação com o método do tanque no qual foi aplicada a maior lâmina parcial acumulada e as parcelas manejadas por tensiometria e Penman-Monteith foram submetidas a um déficit hídrico de 40 e $20 \%$, respectivamente. Como o enchimento de grãos é caracterizado em vários trabalhos como um dos estádios em que o feijoeiro é mais sensível ao déficit hídrico (Doorenbos \& Kassam, 1994; Jadoski et al., 2003; Ávila et al., 2010) reduções significativas na produtividade de grãos e seus componentes são esperadas nessas condições. De fato, os resultados obtidos por Ávila et al. (2010) apontam o preflorescimento, a formação das vagens e o enchimento de grãos como as fases mais sensíveis à deficiência hídrica e a falta de água nesses períodos resultou em queda na produtividade e em alguns dos seus componentes.

Tabela 1. Número de irrigações e lâminas aplicadas com manejo da irrigação pelos métodos de tensiometria, tanque Classe A e Penman-Monteith, e precipitações pluviais efetivas recebidas pelo feijoeiro em cada estádio fenológico da cultura. Cultivar BRS Supremo semeado no início de julho

\begin{tabular}{|c|c|c|c|c|c|c|c|}
\hline \multirow{3}{*}{$\begin{array}{l}\text { Estádios } \\
\text { fenológicos }\end{array}$} & \multicolumn{3}{|c|}{ Tratamentos-Métodos de manejo } & \multirow{3}{*}{$\begin{array}{l}\text { Precipitações } \\
\text { pluviais }^{3} \\
(\mathrm{~mm})\end{array}$} & \multicolumn{3}{|c|}{ Lâminas totais por ciclo } \\
\hline & Tensiometria $^{2}$ & $\begin{array}{c}\text { Tanque Classe A/ } \\
\text { Coeficiente de cultura }\end{array}$ & $\begin{array}{l}\text { Penman-Monteith/ } \\
\text { Coeficiente de cultura }\end{array}$ & & Tensiometria & Tanque Classe A & Penman-Monteith \\
\hline & \multicolumn{3}{|c|}{ Irrigações/Lâminas acumuladas - mm } & & & $(\mathrm{mm})$ & \\
\hline V1 & $2 / 12,78$ & $2 / 12,78$ & $2 / 12,78$ & 0,00 & 12,78 & 12,78 & 12,78 \\
\hline V2 & $2 / 12,78$ & $2 / 12,78$ & $2 / 12,78$ & 0,00 & 12,78 & 12,78 & 12,78 \\
\hline V3 & $0 / 0$ & $1 / 10,96$ & $0 / 0,00$ & $2 / 12,50$ & 12,50 & 23,46 & 12,50 \\
\hline R6 & $3 / 25,75$ & $4 / 29,58$ & $4 / 29,58$ & 0,00 & 25,75 & 29,58 & 29,58 \\
\hline $\mathrm{R} 7$ & $4 / 43,84$ & $7 / 76,72$ & $6 / 65,76$ & 0,00 & 43,84 & 76,72 & 65,76 \\
\hline $\mathrm{R} 8$ & $6 / 65,76$ & $10 / 109,60$ & $8 / 87,68$ & $2 / 11,16$ & 76,92 & 120,76 & 98,84 \\
\hline $\mathrm{R} 9$ & $1 / 10,96$ & $1 / 10,96$ & $0 / 0,00$ & $1 / 10,96$ & 21,92 & 21,92 & 10,96 \\
\hline Totais & $27 / 237,42$ & $40 / 372,77$ & $34 / 307,01$ & $5 / 34,62$ & 272,04 & 407,39 & 341,63 \\
\hline
\end{tabular}

${ }^{1} \mathrm{~V}_{0}$ : germinação; $\mathrm{V}_{1}$ : emergência; $\mathrm{V}_{2}$ : folhas cotiledonares; $\mathrm{V}_{3}$ : primeiro trifólio totalmente expandido; $\mathrm{V}_{4}$ : terceiro trifólio expandido; $\mathrm{R}_{5}$ : botões florais; $\mathrm{R}_{6}$ : floração plena; $\mathrm{R}_{7}$ : formação das vagens; $\mathrm{R}_{8}$ : enchimento das vagens; $\mathrm{R}_{9}$ : maturidade fisiológica; ${ }^{2}$ Manejo da irrigação com tensiômetro e curva característica de retenção de água do solo na tensão crítica de $35 \mathrm{kPa}$; ${ }^{3}$ Considerou-se a precipitação pluvial efetiva no cálculo das lâminas 
Ao analisar as lâminas totais recebidas durante a fase reprodutiva observa-se que o tratamento tensiometria promoveu lâmina total $37 \%$ menor que a maior lâmina total aplicada com o tratamento tanque Classe A enquanto no Penman-Monteith a redução foi de $22 \%$. Caso se considere todo o ciclo, parcelas manejadas com tensiometria receberão menor quantidade total de água por irrigação $(237,42 \mathrm{~mm})$, o que significa uma redução de $36 \%$ em relação à lâmina total média de irrigação aplicada no tratamento tanque Classe A $(372,77 \mathrm{~mm})$. O manejo com Penman-Monteith propiciou lâminas $17,48 \%$ menores que as aplicadas pelo tanque e $22,67 \%$ maiores que as do tratamento tensiometria.

No manejo por tensiometria foi observada certa regularidade nas leituras e houve pouca dispersão nos valores das tensões em relação à média. De fato, Pavani et al. (2008) e Bizari et al. (2009) observaram que a tensão matricial da água no solo é menor e menos variável ao longo do ciclo do feijoeiro em plantio direto, em comparação com os demais sistemas de preparo do solo. Para Andrade et al. (2002), o solo manejado em sistema plantio direto na palha aumenta a capacidade de retenção de água, com consequente melhoria no suprimento de água às plantas.

$\mathrm{Na}$ Tabela 2 são apresentadas as taxas médias da variação da tensão de água no solo obtidas pela relação $\left(\Delta \psi_{\mathrm{m}} / \Delta \mathrm{t}\right)$, em $\mathrm{kPa} \mathrm{d}^{-1}$. As maiores variações ocorreram nos estádios da fase reprodutiva sendo mais acentuadas no estádio $\mathrm{R} 7$ entre 56 e 66 DAS $\left(7,55 \mathrm{kPa} \mathrm{d}^{-1}\right)$. Esses resultados são semelhantes aos obtidos por Chieppe Júnior et al. (2000) em trabalho conduzido próximo ao local de realização do experimento. Os autores trabalharam com tensiômetros instalados nas mesmas profundidades $(0,15$ e $0,30 \mathrm{~m})$ sendo que se obtiveram, nas parcelas em que se avaliou a mesma tensão crítica $(30 \mathrm{kPa})$ durante todo o ciclo, variações semelhantes às observadas neste trabalho. No intervalo de 65 a $67 \mathrm{DAE}$ foram registradas variações de $6 \mathrm{kPa} \mathrm{d}^{-1}$, com média final de $5,10 \mathrm{kPa} \mathrm{d}^{-1}$, muito próxima à média $4,88 \mathrm{kPa} \mathrm{d}^{-1}$ constatada neste trabalho.

Tabela 2. Taxa média da variação na tensão de água no solo em valores absolutos $\left(\mathrm{kPa} \mathrm{d}^{-1}\right)$ nas parcelas manejadas com o tratamento tensiômetro em cada estádio do ciclo fenológico do feijoeiro irrigado, cultivar BRS Supremo, semeado no início de julho

\begin{tabular}{cccc}
\hline \multirow{2}{*}{ Fases } & Estádio da cultura $^{\mathbf{1}}$ & Intervalo & $\boldsymbol{\Delta} \boldsymbol{\Psi}_{\mathbf{m}} / \boldsymbol{\Delta t}$ \\
\cline { 3 - 4 } Vegetativa & V3 & $(\mathbf{D A S})^{\mathbf{2}}$ & $\left.\mathbf{( k P a ~ d}^{-\mathbf{1}}\right)$ \\
- & V4 & $18-26$ & 2,12 \\
Reprodutiva & $\mathrm{R} 5$ & $47-42$ & 3,26 \\
- & $\mathrm{R} 6$ & $49-48$ & 4,26 \\
- & $\mathrm{R} 7$ & $56-66$ & 5,60 \\
- & $\mathrm{R} 8$ & $67-85$ & 7,55 \\
- & $\mathrm{R} 9$ & $86-92$ & 5,49 \\
\hline Média & - & - & 4,88 \\
\hline
\end{tabular}

${ }^{1} \mathrm{~V}_{3}$ : primeiro trifólio totalmente expandido; $\mathrm{V}_{4}$ : terceiro trifólio expandido; $\mathrm{R}_{5}$ : botões florais; $R_{6}$ : floração plena; $R_{7}$ : formação das vagens; $R_{8}$ : enchimento das vagens; $R_{9}$ : maturidade fisiológica; ${ }^{2}$ DAS - dias após a semeadura

As menores lâminas aplicadas com manejo por tensiometria e Penman-Monteith ocasionaram reduções significativas na produtividade do feijoeiro (Tabela 3 ) indicando que a quantidade de água recebida pelas parcelas de tais tratamentos não foi suficiente para suprir as necessidades hídricas da cultura. Conforme colocado por Doorenbos \& Kassam (1994) e em razão do curto período do ciclo do feijoeiro, pequenos períodos de deficiência hídrica podem afetá-lo severamente. Os resultados obtidos se assemelham aos de Pavani et al. (2008) e Lopes et al. (2011); esses autores também observaram maiores produtividades no feijoeiro irrigado manejado com base na evapotranspiração estimada pelo método do tanque Classe A em comparação com manejo por tensiometria; apesar disto, resultados diferentes foram obtidos por Lopes et al. (2004), que compararam o desempenho dos métodos da tensiometria, balanço hídrico e tanque e obtiveram economia de $15 \%$ na água de irrigação aplicada com manejo por tensiometria, sem afetar a produtividade de grãos do feijoeiro.

Tabela 3. Médias de produtividade de grãos do feijoeiro e eficiência no uso da água. Produtividade relativa em relação ao tratamento mais produtivo e lâminas totais de água recebidas pelas parcelas de cada tratamento por irrigação e precipitação pluvial

\begin{tabular}{|c|c|c|c|c|}
\hline Tratamentos & $\begin{array}{c}\text { Lâmina } \\
\text { total } \\
(\mathrm{mm})\end{array}$ & $\begin{array}{l}\text { Produtividade } \\
\left(\mathrm{kg} \mathrm{ha}^{-1}\right)^{4}\end{array}$ & $\begin{array}{l}\text { Prod. } \\
\text { relativa } \\
(\%)\end{array}$ & $\begin{array}{c}\text { Eficiência no } \\
\text { uso da água } \\
\left(\mathrm{kg} \mathrm{mm}^{-1}\right)\end{array}$ \\
\hline \multicolumn{5}{|c|}{ Métodos de manejo } \\
\hline Tensiometria $^{1}$ & 272,04 & $2509,29 \mathrm{c}$ & 71,30 & 9,22 \\
\hline Tanque $^{2}$ & 407,39 & $3519,49 \mathrm{a}$ & 100,00 & 8,64 \\
\hline Penman $^{3}$ & 341,63 & 2977,72 b & 84,61 & 8,72 \\
\hline Média & 340,35 & 3002,17 & - & 8,86 \\
\hline Teste F & - & 18,46 ** & - & $0,75^{\text {ns }}$ \\
\hline CV $(\%)$ & - & 16,84 & - & 3,59 \\
\hline dms (Tukey) & - & 343,54 & - & - \\
\hline
\end{tabular}

${ }^{1}$ Manejo da irrigação com tensiômetro e curva característica de retenção de água do solo; ${ }^{2}$ Tanque Classe A e coeficiente de cultura; ${ }^{3}$ Penman-Monteith e coeficiente de cultura; ${ }^{* *}$ significativo a 0,01 de probabilidade pelo teste $\mathrm{F} ;{ }^{4}$ Médias seguidas de letras distintas na vertical diferem entre si, a 0,05 de probabilidade, pelo teste de Tukey; CV: coeficiente de variação; dms: diferença mínima significativa

Não foram observadas diferenças significativas quanto à eficiência no uso da água, o valor médio observado neste trabalho, $8,86 \mathrm{~kg} \mathrm{~mm}^{-1}$ de água aplicado, foi superior ao intervalo especificado por Doorenbos \& Kassam (1994) que estabelecem, para a cultura do feijoeiro, o valor da eficiência de uso da água na produção de grãos com umidade de $10 \%$ da ordem de 3 a $6 \mathrm{~kg} \mathrm{~mm}^{-1}$. Os resultados obtidos diferem daqueles encontrados por Pavani et al. (2008) em que o manejo de irrigação pelo tanque proporcionou maior eficiência de uso de água pela cultura.

As diferenças de produtividade são devidas, provavelmente, ao fato dos métodos de manejo terem propiciado suprimento de água bastante diferenciado, com valores fora e dentro dos intervalos especificados por Doorenbos \& Kassam (1994) segundo os quais a cultura requer de 300 a $500 \mathrm{~mm}$ de água, dependendo do clima. Isto explica os resultados controversos obtidos em trabalho conduzido por Arf et al. (2004) tendose observado que com todas as lâminas fora dos referidos intervalos, 215 a $287 \mathrm{~mm}$ no primeiro ano e 150 a $254 \mathrm{~mm}$ no segundo, os tratamentos com as menores lâminas propiciaram produtividades de grãos semelhantes às dos tratamentos com maiores lâminas de água, não tendo apresentado diferenças significativas. No entanto, com lâminas diferenciadas como as aplicadas neste trabalho, Silveira et al. (1984) obtiveram 
resultados semelhantes com diferenças significativas na produtividade do feijoeiro. A maior e a menor produtividade foram obtidas com lâmina total de 411 e $173 \mathrm{~mm}$ por ciclo, respectivamente.

Os tratamentos tensiometria e Penman-Monteith propiciaram déficit de 60 e $40 \%$, 43 e 14\%, 40 e $20 \%$, respectivamente, nos estádios R5, R7 e R8. No estádio R6 parcelas manejadas com tensiometria sofreram déficit de $13 \%$ quando comparadas ao tratamento tanque Classe A. Os resultados de reduções de produtividade de 29 e $15 \%$ nos tratamentos tensiometria e Penman-Monteith, respectivamente, foram semelhantes aos observados por Lopes et al. (2011) que verificaram redução significativa de $32 \%$ na produtividade do feijoeiro manejado por tensiometria em relação às parcelas manejadas com método do tanque Classe A.

Quanto ao número de vagens por planta, obteve-se média de 12,77 e a maior e a menor quantidade foram observadas com o manejo pelo método do tanque Classe A e tensiometria, respectivamente. No entanto, os resultados das análises apresentados na Tabela 4 revelaram não haver efeito significativo das lâminas de água aplicadas em função dos métodos de manejo sobre este componente. Resultado semelhante foi obtido por Jadoski et al. (2003) com manejo da irrigação pelo método do tanque Classe A condicionando a aplicação de lâminas acumuladas de $15,30,45$ e $60 \mathrm{~mm}$. Os autores observaram diferenças nos componentes do rendimento de grãos, com exceção no número de vagens por planta. Santana et al. (2008) também não observaram diferenças no número de vagens por planta mesmo com níveis de reposição de água no solo variando de 40 a $160 \%$ da lâmina necessária para elevá-lo à "capacidade de campo". Tais resultados diferem dos observados por Pavani et al. (2008) que obtiveram maior número de vagens no feijoeiro manejado com tanque Classe A quando comparado com o manejo por tensiometria em condições de plantio direto, no inverno.

Tabela 4. Médias do número de vagens planta ${ }^{-1}$, grãos vagem $^{-1}$, massa de 100 grãos e altura da planta de feijoeiro, obtidos com a aplicação das lâminas totais de água estimadas por três métodos de manejo da irrigação

\begin{tabular}{|c|c|c|c|c|}
\hline Tratamentos & $\begin{array}{l}\text { Vagens } \\
\text { planta }^{-1}\end{array}$ & $\begin{array}{c}\text { Grãos } \\
\text { vagem }^{-1(4)}\end{array}$ & $\begin{array}{c}\text { Massa de } \\
100 \text { grãos } \\
\text { (g) }\end{array}$ & $\begin{array}{c}\text { Altura da } \\
\text { planta }^{(4)} \\
\text { (m) }\end{array}$ \\
\hline \multicolumn{5}{|c|}{ Métodos de manejo } \\
\hline Tensiometria $^{(1)}$ & 11,89 & $5,17 b$ & 29,98 & $0,59 \mathrm{c}$ \\
\hline Tanque ${ }^{(2)}$ & 13,68 & $6,22 \mathrm{a}$ & 31,13 & $0,77 \mathrm{a}$ \\
\hline Penman $^{(3)}$ & 12,75 & $6,14 \mathrm{a}$ & 29,34 & $0,70 \mathrm{~b}$ \\
\hline Média & 12,77 & 5,84 & 30,15 & 0,69 \\
\hline Teste F & $1,43^{\text {ns }}$ & $23,82^{\star *}$ & $1,26^{\text {ns }}$ & $38,62^{\star \star}$ \\
\hline CV $(\%)$ & 7,02 & 10,07 & 3,86 & 13,26 \\
\hline dms (Tukey) & - & 0,35 & - & 0,03 \\
\hline
\end{tabular}

(1) Manejo da irrigação com tensiômetro e curva característica de retenção de água do solo; (2) Tanque Classe A e coeficiente de cultura; (3) Penman-Monteith e coeficiente de cultura; ns, ${ }^{\star *}$ não significativo e significativo a 0,01 de probabilidade pelo teste $F$, respectivamente; (4) Médias seguidas de letras distintas na vertical diferem entre si a 0,05 de probabilidade, pelo teste de Tukey; CV: coeficiente de variação; Dms: diferença mínima significativa

A análise de variância revelou haver efeito significativo das lâminas aplicadas com os métodos de manejo da irrigação sobre o número de grãos vagem ${ }^{-1}$. Esses resultados corroboram com os obtidos por Santana et al. (2008) que constataram que tanto a falta quanto o excesso de água provocam má-formação dos grãos indicando que a disponibilidade hídrica adequada durante os estádios fenológicos do feijoeiro pode aumentar o número de óvulos fertilizados por vagem, o que propicia melhores rendimentos.

O efeito significativo do manejo diferenciado sobre o número de grãos por vagem pode ser explicado pela ocorrência de déficit hídrico na floração; no estádio R5 as parcelas dos tratamentos tensiometria e Penman-Monteith receberam, respectivamente, 60 e 40\% menos água que o tanque. Para Jadoski et al. (2003) a redução no rendimento de grãos do feijoeiro pela ocorrência de deficiência hídrica durante o período reprodutivo é ocasionada pela alta taxa de abortamento de óvulos o que, sem dúvida, reduz o número de grãos vagem ${ }^{-1}$.

Não houve efeito significativo das lâminas de irrigação estimadas pelos métodos de manejo da água sobre a massa de 100 grãos. Obteve-se média de 30,15 g para 100 grãos. As médias obtidas foram superiores à média de 100 grãos da cultivar BRS Supremo o que, segundo Costa et al. (2006), apresenta média de massa de 100 grãos de $25 \mathrm{~g}$. Os resultados observados neste trabalho diferem dos obtidos por Pavani et al. (2008) que, de forma similar, avaliaram o desempenho do tanque Classe A e da tensiometria em plantio direto e verificaram efeito dos regimes hídricos diferenciados sobre a massa de 1000 grãos do feijoeiro.

A altura média das plantas na colheita foi $0,69 \mathrm{~m}$ e o aumento nas lâminas de irrigação proporcionou incrementos no crescimento do feijoeiro. Com o manejo pelo método do tanque Classe A, com aplicação da maior lâmina total, $407,39 \mathrm{~mm}$, foram obtidas as plantas mais altas. Com aplicação da menor lâmina, $272,04 \mathrm{~mm}$, pelo método da tensiometria, obtiveram-se plantas $0,18 \mathrm{~m}$ mais baixas.

Os dados obtidos em função da aplicação de lâminas de água reforçam as colocações de Figuerêdo et al. (2008) que confirmaram a possibilidade de obtenção de altos rendimentos do feijoeiro irrigado no Cerrado desde que sejam levados em conta a adoção e o manejo correto das tecnologias relacionadas aos fatores que mais influenciam no rendimento tornando-se um dos mais importantes a disponibilidade hídrica do solo proporcionada pela irrigação.

\section{Conclusões}

1. O feijoeiro em plantio direto no sistema integração lavoura-pecuária apresenta maior produtividade de grãos quando a irrigação é manejada pelo método do tanque Classe A.

2. Plantas de feijoeiro submetidas a déficit hídrico de 21 e $37 \%$ nas fases vegetativa e reprodutiva, respectivamente, têm sua produtividade reduzida em $29 \%$. Déficit hídrico de $22 \%$ na fase reprodutiva é capaz de reduzir a produtividade do feijoeiro em $15 \%$.

3. Dentro do intervalo de 272,04 a $407,39 \mathrm{~mm}$ de água a aplicação de maiores lâminas propicia aumento na produtividade de grãos do feijoeiro.

4. O manejo da irrigação por tensiometria com tensão crítica de $35 \mathrm{kPa}$ propicia reduções de até $40 \%$ nas lâminas de água porém causa reduções na produtividade do feijoeiro. 
5. O número de grãos por vagem e a altura das plantas variam em função do regime hídrico com reduções significativas devido às irrigações com menores lâminas.

\section{Agradecimentos}

Os autores agradecem ao Conselho Nacional de Desenvolvimento Científico e Tecnológico $(\mathrm{CNPq})$ pela concessão da bolsa.

\section{Literatura Citada}

Allen, R. G.; Pereira, L. S.; Raes, D.; Smith, M. Crop evapotranspiration: guidelines for computing crop water requirements. Rome: Food Agriculture Organization of the United Nations, 1998. 301p.

Andrade, R. S.; Moreira, J. A. A.; Stone, L. F.; Carvalho, J. A. Consumo relativo de água do feijoeiro no plantio direto em função da porcentagem de cobertura morta do solo. Revista Brasileira de Engenharia Agrícola e Ambiental, v.6, p.35-38, 2002.

Arf, O.; Rodrigues, R. A. F.; Sá, M E.; Buzetti, S.; Nascimento, V. Manejo do solo, água e nitrogênio no cultivo de feijão. Pesquisa Agropecuária Brasileira, v.39, p.131-138, 2004.

Ávila, M. R.; Barizão, D. A. O.; Gomes, E. P.; Fedri, G.; Albrecht, L. P. Cultivo de feijoeiro no outono/inverno associado à aplicação de bioestimulante e adubo foliar na presença e ausência de irrigação. Scientia Agraria, v.11, p.221-230, 2010.

Barbosa Filho, M. P.; Silva, O. F. Adubação e calagem para o feijoeiro irrigado em solo de cerrado. Pesquisa Agropecuária Brasileira, v.35, p.1317-1324, 2000.

Bizari, D. R.; Matsura, E. E.; Roque, M. W.; Souza, A. L. Consumo de água e produção de grãos do feijoeiro irrigado em sistemas plantio direto e convencional. Ciência Rural, v.39, p.2073-2079, 2009.

Chacín Lugo, F. B. Cursos de avances recientes em eldiseño y análisis de experimentos. Caracas: Universidad Central da Venezuela, 1997. 145p.

Chieppe Júnior, J. B.; Klar, A. E.; Stone, L. F. Efeito de métodos de controle da irrigação no desenvolvimento do feijoeiro (Phaseolus vulgaris L.), sob diferentes tensões de água do solo. Irriga, v.5, p.9-20, 2000.

Costa, J. G. C.; Faria, L. C.; Rava, C. A.; Del Peloso, M. J.; Melo. L. C.; Cabrera Díaz, J. L.; Faria, J. C.; Silva, H. T.; Sartorato, A.; Bassinello, P. Z.; Zimmermann, F. J. P.BRS 7762 Supremo - A black common bean cultivar with erect plant type. Crop Breeding and Applied Biotechnology, v.6, p.182-184, 2006.

Doorenbos, J.; Kassam, A. H. Efeito da água no rendimento das culturas. Campina Grande: Universidade Federal da Paraíba, 1994. 360p.

Dourado Neto, D.; Nielsen, D. R.; Hopmans, J. W.; Reichardt, K.; Bacchi, O. O. S. Soil water retention curve SWRC: Programa para confecção da curva de retenção de água no solo. Version 3.00 beta. Piracicaba: Universidade de São Paulo, 2001. CD-Rom
EMBRAPA - Empresa Brasileira de Pesquisa Agropecuária. Manual de métodos de análise de solo. 2.ed. Rio de Janeiro: Centro Nacional de Pesquisa de Solos, 1997. 212p.

Fancelli, A. L.; Dourado Neto, D. Ecofisiologia e fenologia do feijoeiro. In: Fancelli, A. L; Dourado Neto, D. (coord.) Tecnologia da produção do feijão irrigado. Piracicaba: Escola Superior de Agricultura Luiz de Queiroz, 1997. p.100-120.

Figuerêdo, S. F.; Pozzebon, E. J.; Frizzone, J. A.; Azevedo, J. A.; Guerra, A F.; Silva, E. M. Gerenciamento da irrigação do feijoeiro baseado em critérios técnicos e econômicos no cerrado. Irriga, v.13, p.378-391, 2008.

Freitas Júnior, E.; Silva, E. M. Uso da centrífuga para determinação da curva de retenção de água no solo em uma única operação. Pesquisa Agropecuária Brasileira, v.19, p.1423-1428, 1984.

Jadoski, S. O.; Carlesso, R.; Melo, G. L.; Rodrigues, M.; Frizzo, Z. Manejo da irrigação para maximização do rendimento de grãos do feijoeiro. Irriga, v.8, p.1-9, 2003.

Lopes, A. S.; Oliveira, G. Q.; Souto Filho, S. N.; Goes, R. J.; Camacho, M. A.Manejo de irrigação e nitrogênio no feijoeiro comum cultivado em sistema plantio direto. Revista Ciência Agronômica, v.42, p.51-56, 2011.

Lopes, A. S.; Pavani, L. C.; Corá, J. E.; Zanini, J. R.; Miranda, H. A. Manejo da irrigação (tensiometria e balanço hídrico climatológico) para a cultura do feijoeiro em sistemas de cultivo direto e convencional. Engenharia Agrícola, v.24, p.89-100, 2004.

Morais, N. B.; Bezerra, F. M. L.; Medeiros, J. F.; Chaves, S. W. P. Resposta de plantas de melancia cultivadas sob diferentes níveis de água e de nitrogênio. Revista Ciência Agronômica, v.39, p.369-377, 2008.

Pavani, L. C.; Lopes, A. S.; Galbeiro, R. B. Manejo da irrigação na cultura do feijoeiro em sistemas plantio direto e convencional. Engenharia Agrícola, v.28, p.12-21, 2008.

Reis, E. F.; Bragança, R.; Garcia, G. O.; Pezzopane, J. E. M.; Tagliaferre, C. Estudo comparativo da estimativa da evapotranspiração de referência para três localidades do estado do Espírito Santo no período seco. Idesia, v.25, p.75-84, 2007.

Santana, M. J.; Caravalho, J. A.; Andrade, M. J. B.; Braga, J. C.; Gervásio, G. G. Coeficiente de cultura e análise do rendimento do feijoeiro sob regime de irrigação. Irriga, v.13, p.92-112, 2008.

Santana, M. J.; Carvalho, J. A.; Andrade, M. J. B.; Gervásio, G. G.; Braga, J. C.; Lepri, E. B. Viabilidade técnica e econômica da aplicação de água na cultura do feijoeiro comum (Phaseolus vulgaris L.). Ciências e Agrotecnologia, v.33, p.532-538, 2009.

Silveira, P. M.; Steinmetz, S.; Guimarães, C. M.; Aidar, H.; Carvalho, J. R. P. Lâminas de água e turnos de rega na cultura do feijoeiro de inverno. Pesquisa Agropecuária Brasileira, v.19, p.219-223, 1984.

Silveira, P. M.; Stone, L. F. Manejo da irrigação do feijoeiro: Uso do tensiômetro e avaliação do desempenho do pivô central. Goiânia: Embrapa Arroz e Feijão, 1994. 46p.

Snyder, R. L. Equation for evaporation pan to evapotranspiration conversion. Journal of Irrigation and Drainage Engineering, v.118, p.977-980, 1992. 
Stone, L. F.; Silva, S. C. Uso do tanque Classe A no controle da irrigação do feijoeiro no sistema plantio direto. Pesquisa em foco, n.25, Santo Antônio de Goiás: Embrapa Arroz e Feijão, 1999. 2p. van Genuchten, M. T. A closed-form equation for predicting the hydraulic conductivity of unsaturated soils. Soil Science Society of America Journal, v.44, p.892-898, 1980. 